\title{
SISTEMA CARCERÁRIO BRASILEIRO: BREVES ANOTAÇÕES SOBRE FATORES QUE SUGEREM A INEFICIÊNCIA DA PENA PRIVATIVA DE LIBERDADE
}

\author{
Bárbara Willeny Krug, Eduardo Buzetti Eustachio Bezerro \\ Universidade do Oeste Paulista - UNOESTE, curso de Direito, Presidente Prudente, SP. E-mail: \\ eduardobuzetti@hotmail.com
}

\begin{abstract}
RESUMO
A busca pela eficácia no sistema prisional vem gerando debates dos direitos inerentes aos detentos, observando as proibições de violações dos Direitos designados na Carta Magna. Além do mais implica considerar fatores que levam a ver que conforme a aplicação da pena privativa de liberdade violando os direitos dos presos, as falhas contidas no sistema sugerem uma inércia quanto à ressocialização do condenado, não dando oportunidades de inserção no convívio da sociedade quiçá manter as garantias e direitos contidos na Constituição Federal e de demais órgãos de regulamentação. Faço vista de que, o presente artigo sugere uma temática abordando os principais fatores que levam a uma inércia processual.
\end{abstract}

BRAZILIAN PRISON SYSTEM: BRIEF NOTES ON FACTORS THAT SUGGEST AN INEFFICIENCY OF PRIVATE PENALTY OF FREEDOM

\begin{abstract}
The quest for efficiency in the prison system has generated debates the rights attached to detainees and observing the prohibitions of violations of rights designated in the Constitution. Moreover implies considering factors that lead to see that as the application of deprivation of liberty in violation of the rights of prisoners, the deficiencies in the system suggest inertia as the rehabilitation of the convict, giving insertion opportunities in the conviviality of society perhaps keep the rights and guarantees contained in the Constitution and other regulatory agencies. I view that, this article suggests a theme addressing the main factors that lead to procedural inertia.
\end{abstract}




\title{
1 INTRODUÇÃO
}

A privação da liberdade num todo vem sendo analisada como aspecto social pelo fato de apresentar características vistas de que o sistema carcerário apresenta condições inadequadas de sobrevivência para os presos e que em regra vivem em um descaso gerado por vários conflitos, o que dificulta ainda mais a discussão.

Contudo, há certa relevância e atenção ante a esta conclusão, pois devem ser tema de uma perspectiva relativamente questionável. O sistema carcerário vem sofrendo com o descaso de nossos governantes sobremaneira de que não atua de forma precisa na reintegração dos detentos e assim fazendo com que as cadeias públicas fiquem superlotadas estagnando o Poder Público.

Sendo assim, ainda digo que a pena de privação à liberdade não seria apenas de desintegrar da sociedade aqueles indivíduos que se considerariam uma ameaça à sociedade, mas sim aplicar métodos de ressocialização dentro da pena privativa de liberdade sempre atento de forma legal aos princípios do homem, respeitando os direitos inerentes a sua condição de viver.

A pesquisa desenvolver-se-á a partir dos métodos científicos dedutivos e dialético, fundamentada em levantamento bibliográfico, legislativo e estatístico.

\section{A DECLARAÇÃO UNIVERSAL DOS DIREITOS HUMANOS EM SEU ASPECTO PRISIONAL}

Os direitos e garantias trazidos pela Constituição de 1988 e pela Declaração Universal de Direitos Humanos são que o homem deve possuir o máximo de dignidade cuja preponderância recai, sobretudo, no combate a arbítrios do Estado.

Luiz Alberto David Araújo e Vidal Serrano Junior (2011, pp. 71-72), em sua obra, lecionam que:

\begin{abstract}
"Os Direitos Fundamentais constituem uma categoria jurídica, constitucionalmente erigida e vocacionada à proteção da dignidade humana em todas as dimensões. Destarte, possuem natureza poliédrica, prestando-se ao resguardo do ser humano na sua liberdade (direitos e garantias individuais (, nas suas necessidades (direitos econômicos, sociais e culturais) e na sua preservação (direitos à fraternidade e à solidariedade)." 1
\end{abstract}

Ainda, segundo o autor, os direitos individuais podem ser vistos de um enfoque chamado "enfoque jurídico positivo", no qual apresenta os direitos individuais como cláusulas estatais, fazendo com que o Estado atribua direito que somente lhes são destinados. Também os direitos coletivos como transindividuais, de natureza indivisível, ou seja, direitos difusos, chamados de

\footnotetext{
${ }^{1}$ Luiz Alberto David Araújo e Vidal Serrano Junior. Curso de Direito Constitucional. São Paulo, Verbatim, 2011, p. 71-72. 
exercícios coletivos. Não se pode deixar de citar os direitos sociais dispostos no artigo 6 da Constituição Federal, evidenciando a questão da segurança e assistência.

\section{FATORES DE INEFICIÊNCIA DA LEI DE EXECUÇÃO PENAL - LEI № 7.210/84}

O que se pode imaginar de uma penitenciária é de aspecto um tanto quanto degradante, visto do prisma de que ela só possui em suas características físicas obstáculos que dificultam qualquer ato que extrapole os limites da pena privativa de liberdade.

Antes das cadeias públicas tomarem esse aspecto, eram consideradas verdadeiras masmorras e calabouços, onde os presos aguardavam não a sentença que determinaria o tempo de prisão, mas sim a sentença que acarretaria em torturas, maus tratos e morte.

Com o passar do tempo, os presídios aprimoraram o sistema, dando sistematização às portas, maior segurança deixando de ter uma visão primária do que apresentava, melhor alimentação dos detentos, atendimento jurídico e médico, e outros fatores que nos levam a crer a melhora do sistema prisional.

Todavia, ainda não foram dizimados do cotidiano prisional alguns acontecimentos que favorecem o aumento da criminalidade dentro e fora do sistema. E os principais causadores são a violação dos princípios dos direitos dos homens, os quais deveriam ser respeitados pelos aplicadores da lei.

Com base no artigo 5, inciso III, da Constituição Federal há justamente o resguardo de tratamento desumano, degradante e tortura, ao preconizar que "ninguém será submetido à tortura nem a tratamento desumano ou degradante".

Não há que se discutir que a vida dentro de uma prisão não seria de sobremaneira fácil, pois, trata-se de um ambiente onde se vive em plena desconfiança e desonestidade. Quando um indivíduo ingressa no sistema prisional, pode-se dizer que há uma desorganização de personalidade, segundo João Faria Junior (apud ARAUJO e JUNIOR, 2011, p. 96): “A prisionização leva à desorganização da personalidade, à deformação do caráter, à degradação do comportamento e ao abandono dos padrões de conduta da vida extramuros".

Ademais, quando ingresso na população carcerária o preso admite para si hábitos para busca de sua própria personalidade dentro do presídio atribuindo a si modo do vestuário, linguajar adequado para o ambiente, também como atividades que praticara no sua dia-a-dia, obediência aos funcionários e presos de comando e também a realização de pactos com facções criminosas. 
A retirada da liberdade de alguém é considerada uma limitação ao livre arbítrio inerente ao ser humano que devasta e rompe todo laço entre o preso e sua família, trabalho, amigos e convívio na sociedade, sendo dita como uma morte civil tendo retirados muitos de seus direitos.

A intensidade de estar preso sem poder exercer costumes de seu cotidiano faz com que os presos assumam uma personalidade antes não conhecida por eles mesmos. Tomando atitudes para a adequação e propriedade de seu próprio espaço e a busca pela liderança e um novo eu dentro dos presídios, tais atitudes tem como resultado motins, rebeliões, fugas e muitas vezes acarretando em mortes e reféns.

Nos presídios há um alto índice de contaminação de doenças sexualmente transmissíveis, porque o preso não possui uma relação heterossexual e sim homossexual, que acaba tendo relações com tantos outros homens, tornando-se um ambiente promíscuo e altamente insalubre. Igualmente, doenças como tuberculose, H1N1, hepatites B e C, são facilmente contraídas no ambiente prisional, ante a falta de atendimento médico, o que propicia a rápida contaminação.

Além do mais, a superlotação dos presídios vem sendo considerado o maior dos problemas nas unidades prisionais não só no Estado de São Paulo, mas em todo o Brasil. É importante dizer que é quase impossível à convivência dentro de um espaço tão pequeno para tantos presos e suas várias personalidades.

Conforme específico estudo:

"O Brasil como a maioria dos países latino-americanos, assiste imobilizado ao desenvolvimento de uma crise crônica em seu sistema penitenciário. Especialmente nesta última década, os indicadores disponíveis a respeito da vida nas prisões brasileiras demonstram de maneira inconteste um agravamento extraordinário de problemas já muito antigos como a superlotação carcerária, a escalada de violência entre os internos, às práticas de abusos, maus-tratos e torturas sobre eles, a inexistência de garantias mínimas aos condenados e o desrespeito sistemático e institucional à legislação ordinária e aos princípios dos direitos humanos." (ROLIM, 2003, p. 121).

Um dos maiores influenciadores da superlotação prisional se dá pelo fato de que muitos dos presos são provisórios, ou seja, estão aguardando julgamento. Os mesmos ficam abrigados juntamente com os presos que já foram condenados, nos quais esses provisórios deveriam estar em ambiente separados dos demais. Acontece que com essa mistura de presos condenados e provisórios há uma repleta diversidade de personalidades abrigadas em um mesmo recinto gerando mais conflitos e relações de promiscuidade, ferindo o princípio da dignidade da pessoa humana assegurada pela Constituição Federal de 1988 em seu artigo 5o, inciso XLIX, e também 
remetidos ao artigo 38 do Código Penal ${ }^{2}$. A lentidão processual no que diz respeito aos julgamentos de presos provisórios é o fator que mais congestiona as cadeias públicas, porque os detentos sem julgamentos ficam mais tempo preso do que realmente deveriam ficar.

Outro motivo também seria a reincidência, pois os presos voltariam ao sistema prisional pela falta de ocupação fora das cadeias, porque geralmente os mesmos quando retornam as ruas nem sempre encontram um trabalho justamente por serem ex-detentos ou pela falta de ocupação educacional e formação profissional, voltando assim ao mundo do crime.

No artigo 84 da Lei de Execução Penal, tem-se que o preso provisório deve ficar em local separado do condenado por sentença transitada em julgado, ao passo que o preso primário deve cumprir a pena privativa de liberdade em seção distinta daquela reservada para os reincidentes.

No entanto, a superlotação além da falta de vagas se dá por conta de que há presos que já cumpriram a pena ou aguardam remoção de regime não foram removidos ou postos em liberdade.

\section{O INVESTIMENTO PÚBLICO INEFICAZ}

Essa é uma realidade presente em nossas cadeias brasileiras. Há vários acontecimentos no momento atual que se deu por este motivo talvez pudéssemos dizer que a falta de investimento nos presídios, a baixa escolaridade dos detentos, a falta de informação e outras razões que justificassem esse problema.

Porém, os governos federal e estadual vêm investindo muito mais nos presídios do que se pode parecer, pois há um apontamento de que o governo chega a investir mais que 1,1 bilhão de reais na construção não só de vagas mas também nas condições de dignidade e segurança.

Segundo artigo publicado na Revista Carta Capital (2015, p. 1), o Brasil ocupa o 4o (quarto) lugar no ranking dos países com maior número de população carcerária, sendo que até o ano de 2014 apresentava grande crescimento no total de presos vindo a ser cerca de $161 \%$ até junho de 2014, com base desde o ano de 2000. Pode-se ainda afirmar que apresentadas essas condições o número de funcionários no sistema ocupa uma discrepância absolutamente notável, pois em média para 400 (quatrocentos) presos há somente 1 (um) funcionário, indo mais além a cada quatro presídios possui dois presos por vaga. Com esses dados o crescimento populacional do sistema prisional vem aumento de uma maneira exorbitante, dando um ritmo que o Brasil é o segundo país que mais prendeu pessoas nos últimos 15 (quinze) anos, chegando a ser uma

\footnotetext{
${ }^{2}$ Código Penal Brasileiro, art. 38: "O preso conserva todos os direitos não atingidos pela perda da liberdade, impondo-se a todas as autoridades o respeito à sua integridade física e moral".
} 
porcentagem de 7\% ao ano. Se esse crescimento for mantido o Brasil chegará a ter cerca de 1 milhão de presos em 2022, este é um dado um tanto quanto assustador a medida de proporção relativas ao déficit de vagas que as unidades prisionais possuem.

Contudo, a falta de interesse ao melhoramento das prisões não se leva apenas ao investimento material, ou seja, esse investimento deveria ser direcionado ao aprimoramento do estudo, habilidades manuais e intelectuais dos presos, e também com a oportunidade de uma nova perspectiva. No mais, deveria haver um maior empenho do Estado ao subsidiar aparatos que proporcione ao detento uma perspectiva diferente da vivida dentro dos sistemas prisionais.

\section{VIOLAÇÃO DOS DIREITOS INERENTES AO PRESO}

No sistema carcerário é fácil encontrar a maior violação de todos os direitos que a Constituição Federal de 1988 nos dá, como dito alhures temos o da dignidade da pessoa humana que por sua vez pode ser destacado não só na Constituição Federal, mas também no Código Penal e Lei de Execução Penal.

A Lei de Execução Penal, em seu artigo 40, traz como deveria ser a aplicação da lei em face do respeito à dignidade do preso, da seguinte forma: "Impõe-se a todas as autoridades o respeito à integridade física e moral dos condenados e dos presos provisórios".

Vale ainda dizer que em um âmbito onde vive cerca de duas ou mais pessoas por espaço, não há o que debater sobre a relevância da segurança e a discutir sobre a dignidade do preso, pois são fatores que geram mais debates a luz das desordens no sistema. Não só a segurança e a dignidade são princípios resguardados, no entanto, há também o princípio de respeito ao preso resguardado pela Constituição Federal, abolindo ações de torturas e maus tratos e condições desumanas, sem contar com a descriminação da sociedade em um todo.

Podemos observar que a Lei de Execução Penal (Lei no 7.210/84), surgiu para efeitos que garantisse ao preso maior efetivação dos processos dando celeridade processual com vistas a proporcionar condições para a harmônica integração social do sentenciado (artigo 1ㅇ).

A Constituição Federal, no artigo 5o, exemplifica os direitos dos presos como o de qualquer outra pessoa, excluindo-se apenas o direito à liberdade.

Nesse aspecto, dispõe a Constituição que: "Todos são iguais perante a Lei, sem distinção de qualquer natureza, garantindo-se aos brasileiros e aos estrangeiros residentes no País a inviolabilidade do direito à vida, à liberdade, à igualdade, à segurança e à propriedade", e explicita que: ninguém será obrigado a fazer ou deixar de fazer alguma coisa senão em virtude da Lei (inciso II); ninguém será submetido à tortura nem a tratamento desumano ou degradante (inciso III); é livre a 
manifestação do pensamento sendo vedado o anonimato (inciso IV ); é inviolável à liberdade de consciência e de crença, sendo assegurado o livre exercício dos cultos religiosos e garantida, na forma da lei, a proteção aos locais de culto e suas liturgias (inciso VI); é assegurada, nos termos da lei, a prestação de assistência religiosa nas entidades civis e militares de internação coletiva (inciso VII); ninguém será privado de direitos por motivo de crença religiosa ou de convicção filosófica ou política para se invocar, para eximirse de obrigação legal a todos imposta e recusar-se a cumprir prestação alternativa, fixada em lei (inciso VIII).

Sopese-se que os presos possuem, também, o direito à inviolabilidade de suas correspondências, aderência à manifestação religiosa e liberdade de consciência.

Pondera Muakad (1998, p. 24) que: "A prisão deve ter o mesmo objetivo que tem a educação da infância na escola e na família; preparar o indivíduo para o mundo a fim de subsistir ou convier tranquilamente com seus semelhantes".

Como solução para esses conflitos de interesses propõe-se um acordo entre as políticas criminais e as penitenciárias, ao passo de que as políticas criminais apresentariam formas para o suprimento da superlotação carcerária, desta forma, incluiria a sociedade em conjunto para apresentação de ideias nas quais diminuíssem a criminalidade. Já as penitenciárias visando a diminuição de população já existente, deve buscar a eficiência na aplicação de estudos e formas de aprimoramento do caráter dos detentos. Destarte, ambas as ações deveriam ser aplicadas de forma conjunta para um melhor resultado.

De resto, Anabela Miranda Rodrigues, afirma que: "Já não se questiona a sua finalidade socializadora e o problema principal são as condições de sua execução." (2001, p. 174).

\section{CONCLUSÃO}

O problema do sistema prisional não é algo somente dos dias atuais já que vem sendo tratado de muitos outros tempos, porém, não tem se visto discussões sobre o tema porque o Estado buscar manter a ordem e abafar os problemas a ele imposto. Sabemos que a prisão trabalha como órgão punitivo, mas não agindo de maneira somente punitiva, mas também como órgão encorajador para a melhoria não só do preso, em conjunto com o sistema em um todo.

A ineficácia da atuação governamental não reduz os altos índices de precariedade, muito pelo contrário a inércia na operabilidade das normas e leis faz com que aumente cada vez mais o número de presos sem qualquer expectativa. O sistema carcerário deve, contudo, ser observado como garantidor dos direitos reluzentes ao preso, seja relacionado a ações ou omissões como resolução, em busca da solução para o problema. 


\section{REFERÊNCIAS}

CONSTITUIÇÃO DA REPÚBLICA FEDERATIVA DO BRASIL DE 1988. São Paulo: Saraiva, 2014.

ARAUJO, Luiz Alberto David; JÚNIOR, Vidal Serrano Nunes. Curso de direito Constitucional. 16. ed. São Paulo: Verbatim, 2011.

BATISTA, Nilo. Punidos e Mal pagos: Violência, justiça, segurança pública e direitos humanos no Brasil de hoje. São Paulo: Revan, 1990.

BECHARA, Evanildo. Dicionário da Língua Portuguesa Evanildo Bechara, atualizado pelo novo acordo ortográfico: 51.210 entradas (verbetes e locuções). Rio de Janeiro: Nova Fronteira, 2011.

LEI № 7.210, de 11 de julho de 1984. 16. ed. São Paulo: Saraiva, 2008.

MEDEIROS, Gerlania Araújo de. A precariedade no sistema penitenciário brasileiro: violação dos direitos humanos. Disponível em: <http://www.ambitojuridico.com.br/site/?artigo_id=10363\&n_link=revista_artigos_leitura>. Acesso em 14 ago 2015.

OLIVEIRA, Odete Maria de. Prisão: um paradoxo social. 2.ed. Florianópolis: Daufsc, 1996.

PELLEGRINI, Marcelo. Brasil possui a quarta maior população prisional do mundo. Disponível em: <http://www.cartacapital.com.ber/sociedade/brasil-possui-a-quarta-maior-populacao-prisionaldo-mundo-7555.html>. Acesso em 14 ago 2015.

RODRIGUES, Anabela Miranda. Novo Olhar sobre a Questão Penitenciária. São Paulo: Revista dos Tribunais, 2001.

VASCONCELOS, Emerson Diego dos Santos de; QUEIROZ, Ruth Fabrícia de Figueroa; CALIXTO, VIANA, Johnnatan Reges. A crise sobre o sistema carcerário brasileiro. Disponível em:

<http://www.ambito-juridico.com.br/site/?n_link=revista_artigos_leitura\&artigo_id=12228>. Acesso em 14 ago 2015. 